\title{
Graphical Synopsis
}

\section{Inorganic Crystal Structures}

Hans Grimmer and Bernard Delley Density functional theory calculations of merohedric twinning in $\mathrm{KLiSO}_{4}$

https://doi.org/10.1515/zkri-2018-2126

Z. Kristallogr. 2019; 234(4): 211-217
Synopsis: Whereas for $\mathrm{KLiSO}_{4}$ crystals grown from aqueous solutions low twin energy is connected with high frequency of occurrence, for the formation of transformation twins the availability of twin nuclei plays a major role. The same holds also for twinning in quartz.
Lars Robben, Isaac Abrahams, Michael Fischer, Stephen Hull, Martin T. Dove and Thorsten M. Gesing

Low-temperature anharmonicity and symmetry breaking in the sodalite $\left|\mathrm{Na}_{8} \mathrm{I}_{2}\right|\left[\mathrm{AlSiO}_{4}\right]_{6}$

https:// doi.org/10.1515/zkri-2018-2122

Z. Kristallogr. 2019; 234(4): 219-228
Synopsis: Low temperature anharmonicity revealed by total scattering experiments explains unusual thermal expansion behaviour of iodide sodalite $\left|\mathrm{Na}_{8} \mathrm{I}_{2}\right|\left[\mathrm{AlSiO}_{4}\right]_{6}$.
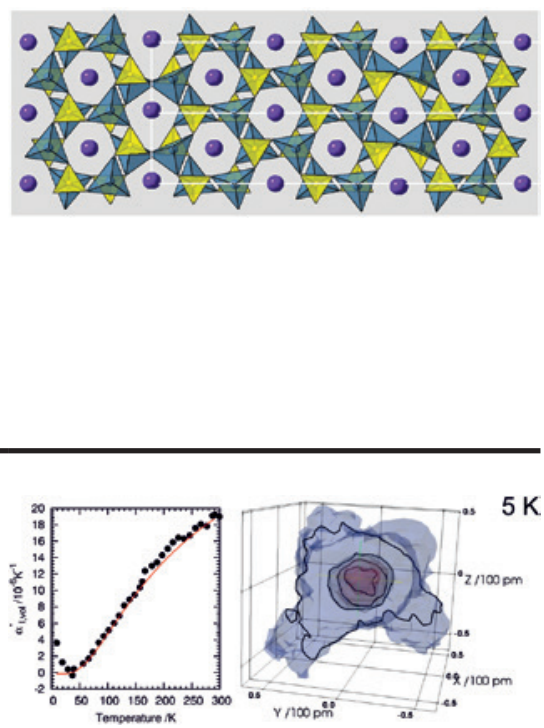

Jerry Joe E.K. Harrison, Moscoh Daniel Ayine-Tora, Benjamin Appiagyei, Felix C. Mills-Robertson, William A. Asomaning, Daniel G. Achel, Hiroyuki Ishida and Robert Kingsford-Adaboh

Crystal structure and in vitro antimicrobial activity studies of Robustic acid and other Alpinumisoflavones isolated from Millettia thonningii

https:// doi.org/10.1515/zkri-2018-2052

Z. Kristallogr. 2019; 234(4): 229-235
Synopsis: This study reports the crystal structure of robustic acid and its bond topological properties obtained from refinements using the independent atom model and the invariom model. In vitro antimicrobial and antioxidant activity studies of other Alpinumisoflavones isolated from Millettia thonningii are also discussed.

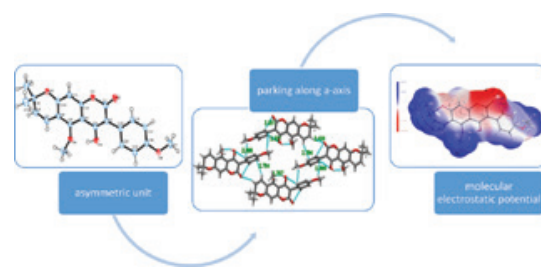


Valentin Kraposhin, Alexander Talis and Nenad Simich-Lafitskiy

The symmetry origin of the austenitecementite orientation relationships in steels

https://doi.org/10.1515/zkri-2018-2108

Z. Kristallogr. 2019; 234(4): 237-245
Synopsis: Crystal structures of the iron FCC modification (austenite) and $\mathrm{Fe}_{3} \mathrm{C}$ carbide can be transformed into each other by diagonal flipping in a rhombus consisting of two

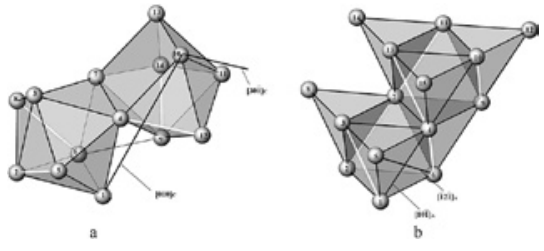
adjacent triangular faces. This transformation mechanism determines orientation relationship between austenite and $\mathrm{Fe}_{3} \mathrm{C}$ carbide which has been observed in many experiments.

\section{Organic and Metalorganic Crystal Structures}

Olga A. Chekhomova, Vladislav V. Klepov, Denis V. Pushkin, Evgeny V. Alekseev, Anna V. Vologzhanina, Larisa B. Serezhkina and Viktor N. Serezhkin Structural features of uranyl acrylate complexes with s-, p-, and d-monovalent metals

https://doi.org/10.1515/zkri-2018-2089

Z. Kristallogr. 2019; 234(4): 247-256
Synopsis: A series of uranyl acrylate complexes with monovalent cations was obtained and structurally characterized. The structure is a function of the nature and the size of the monovalent cations. The acrylate anion enhances connectivity in a uranyl structure by Ag-C bonding.
Carina Schlesinger, Michael Bolte and Martin U. Schmidt

Challenging structure determination from powder diffraction data: two pharmaceutical salts and one cocrystal with $Z^{\prime}=2$

https://doi.org/10.1515/zkri-2018-2093

Z. Kristallogr. 2019; 234(4): 257-268
Synopsis: The limits of structure solution by real-space methods are explored based on organic structures with 23-31 degrees of freedom. Two structures could be solved without problems; the third one (see figure) could not.
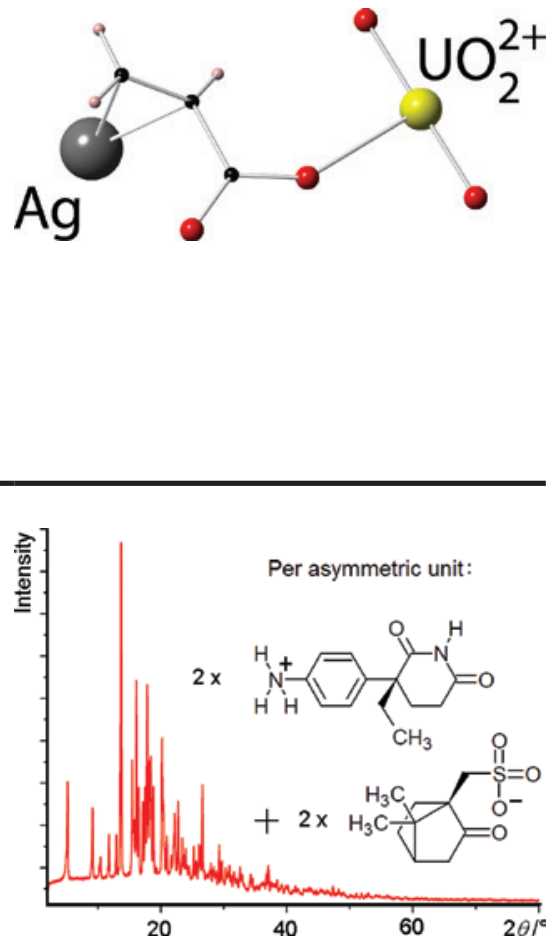

Huijun Li, Yaling He, Qingqing Li, Zhouqing Xu, Yan Wang and Yuan Wang Synthesis of CdSe/ZnS@HPU-2 composites for highly sensitive and multicolor florescence response to $\mathrm{Fe}^{3+}$

https://doi.org/10.1515/zkri-2018-2130

Z. Kristallogr. 2019; 234(4): 269-276
Synopsis: A hybrid material based dual-emission probe for $\mathrm{Fe}^{3+}$ was prepared by the hybridization of a threedimensional framework and CdSe/ZnS QDs-doped silica nanoparticles.

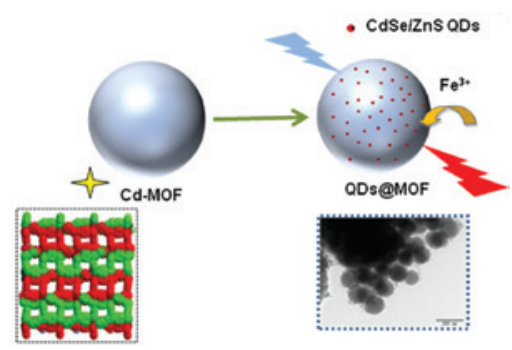




\section{Letter}

Laura Henry, Volodymyr Svitlyk, Gaston Garbarino, David Sifre and Mohamed Mezouar

Structure of solid chlorine at $1.45 \mathrm{GPa}$

https://doi.org/10.1515/zkri-2018-2145

Z. Kristallogr. 2019; 234(4): 277-280
Synopsis: Structure of solid chlorine at $1.45 \mathrm{GPa}$ featuring chains of $\mathrm{Cl} 6$ clusters propagating along the $c$ direction.

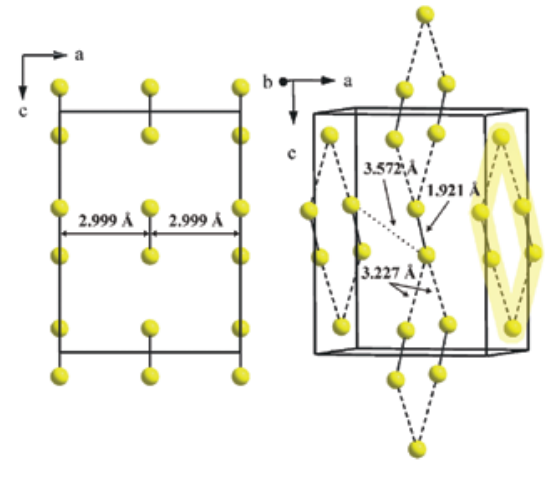

Formulae Index 